NASA CONTRACTOR R E POR T
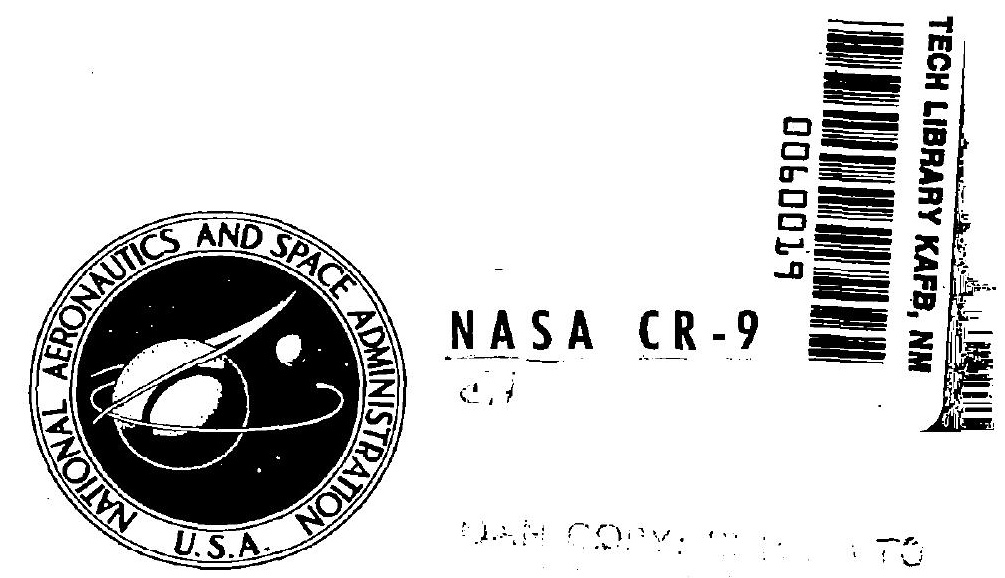

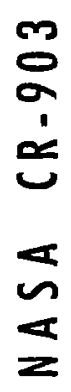

STABILIZATION SYSTEM ANALYSIS

AND PERFORMANCE OF THE

GEOS-A GRAVITY-GRADIENT

SATELLITE (EXPLORER XXIX)

by V. L. Pisacane, P. P. Pardoe, and B. J. Hook

Prepared by

THE JOHNS HOPKINS UNIVERSITY

APPLIED PHYSICS LABORATORY

Silver Spring, Md.

for

NATIONAL AERONAUTICS AND SPACE ADMINISTRATION - WASHINGTON, D. C. - OCTOBER 1967 
NASA CR-903

\section{STABILIZATION SYSTEM ANALYSIS AND PERFORMANCE OF THE GEOS-A GRAVITY-GRADIENT} SATELLITE (EXPLORER XXIX)

By V. L. Pisacane, P. P. Pardoe, and B. J. Hook

Distribution of this report is provided in the interest of information exchange. Responsibility for the contents resides in the author or organization that prepared it.

Issued by Originator as Report No. TG-901

Prepared under Contract No. W-12014 by

THE JOHNS HOPKINS UNIVERSITY

APPLIED PHYSICS LABORATORY

Silver Spring, Md.

for

NATIONAL AERONAUTICS AND SPACE ADMINISTRATION

For sale by the Clearinghouse for Federal Scientific and Technical Information Springfield, Virginio 22151 - CFSTl price $\$ 3.00$ 
Page

ABSTRACT

NOMENCLATURE

INTRODUCTION

ATTITUDE DETERMINATION SYSTEM

STABILIZATION SYSTEM DESCRIPTION

ATTITUDE SIMULATION

PRELAUNCH DESIGN STUDY

POST-LAUNCH ANALYSIS

POST-LAUNCH ATTITUDE DETECTION

SYSTEM PERFORMANCE

COMPARISON OF THEORETICAL AND

EXPERIMENTAL ATTITUDE DATA

6

APPENDIX A - STEADY-STATE LIBRATION INDUCED BY ORBIT ECCENTRICITY

APPENDIX B - SIMPLIFIED STUDY OF THE

MAGNETICALLY ANCHORED DAMPER

ACKNOWLEDGMENT

12

REFERENCES

12 


\section{LIST OF ILLUSTRATIONS}

Figure

Page

1

GEOS-A SPACECRAFT

7

2

OUTPUT OF 4 GEOS-A LAMPS FLASHED

SIMULTANEOUSLY BASED ON PROTOTYPE

LAMP-REFLECTOR MEASUREMENTS.

ANNA BEAM PATTERN IS SHOWN FOR

COMPARISON

GEOS-A SOLAR ATTITUDE DETECTOR

RESPONSE CURVES

AMPLITUDE OF ROLL ANGLE VERSUS ANGLE

OF NODE FROM EARTH-SUN LINE, GEOS-A

IN NOMINAL ORBIT AND 50 FOOT BOOM

LENGTH

AMPLITUDE OF ROLL ANGLE VERSUS ANGLE OF NODE FROM EARTH-SUN LINE, GEOS-A NOMINAL ORBIT

GEOS-A INVERSION MANEUVER STUDY RESULTS, MAXIMUM AMPLITUDE AFTER INVERSION

AS FUNCTION OF COAST TIME AND INITIAL ANGULAR RATE

GEOS-A TRANSIENT SIMULATION RUN

GEOS-A STEADY-STATE SIMULATION RUN, DAY 329

GEOS-A TELEMETRY DATA ILLUSTRATING

DISCONTINUOUS RESPONSE IN - X

COSINE DETECTOR

10 GEOS-A SOLAR COSINE DETECTOR DATA FOR APL/SANTIAGO PASS ON DAY 329 
11 GEOS-A MAGNETOMETER DATA FOR APL/ SANTIAGO PASS ON DAY 329

GEOS-A ATTITUDE DATA AND SIMULATION RESULTS FOR APL/SANTIAGO PASS DAY 329

13 SIMULATION AND $Z$ DETECTOR RESULTS FOR APL/SANTIAGO PASS DAY 329 • 10

14 GEOS-A ATTITUDE DATA AND SIMULATION RESULTS FOR APL PASS ON DAY 338 . 10

15 GEOS-A ATTITUDE DATA AND SIMULATION RESULTS FOR APL PASS ON DAY 339 . 10

16 GEOS-A ATTITUDE DATA AND SIMULATION RESULTS FOR APL PASS ON DAY 340

17 IN-PLANE CONFIGURATION OF SPACECRAFT IN ORBIT 
STABILIZATION SYSTEM ANALYSIS AND PERFORMANCE OF THE GEOS-A GRAV ITY-GRADIENT SATELITITE (EXPLORER XXIX)

Vincent L. Pisacane, Engineer

Peter P. Pardoe, Physicist

B. Joy Hook, Mathematician

The Johns Hopkins University

Applied Physics Laboratory

Silver Spring, Maryland

\section{Abstract}

This paper discusses the stabilization system analysis and orbital performence of the GEOS-A gravity-gradient satel]ite which was luunched into orbit on 6 November 1965. The analys is is performed with the aid of a rather general digital simulation of the non-linear differential equations of motion. It includes the effects of gravity-gradient forces, orbital eccentricity, eddy current dampers, residual magnetic dipoles, solar radiation pressure, and thermal distortion of the spacecraft's stabilization boom.

The allitude messuring system abcard lhe spacecraft is described, and processing of the attitude date is discussed. Description of failures in the attitude determination system and discussion of the subsequent effects on the experimental attitude results are included. Experimental attitude results are compered with the results of the digital simulation. General agreement is obtained.

\section{Nomenclature}

$$
\begin{aligned}
& \text { a = semi-mejor exis } \\
& \mathrm{E} \quad=\text { light intensity } \\
& \mathrm{H} \quad=\text { magnitude of geomagnetic field } \\
& \mathrm{H}_{\mathrm{O}} \quad=\text { magnitude of geomegnetic field at mag- }
\end{aligned}
$$

\section{Introduction}

The purpose of this paper is to discuss the design analysis and flight performance of the stabiIization system of one of the Geodetic Earth Orbiting Satellites, GEOS-A. Geocentric stabilization is achieved in a completely passive manner by utilization of the gravity-gradient principle and a passive energy dissipator. The system analysis is accomplished through a digital solution. of the equations of motion which describes the orientation of the spacecraft in orbit. Flight performance is obtained by an on-board attitude measuring system which determines the orientation of the satcllitc-sun line and magnetic field vector in the satellite reference system. A comparison of the theoretical and measured orientation of the spacecraft concludes the paper.
The repeated success of passive gravity-gradient stabilization systems at low altitudes has fostered interest in the use of this technique for communication and meteorological satellites at higher altitudes with correspondingly more severe requirements on system performance. Since the gravity-gradient restoring torque is inversely proportional to the cube of the distance of the spacecraft from the center of the earth, increased altitude requirements demand a more precise knowledge of the effects of the disturbing forces. At synchronous altitudes the restoring torque is two orders of ragnilude smeller than at low altitudes. For this reason, verification of the performance of gravity-gradient stabilization systems becomes an important consideration.

GEOS-A was conceived as part of the National Geodetic Satellite Program to study geometric and gravimetric geodesy. Geometric geodesy utilizes the principles of triangulation to map the surface of the earth. The study of the gravitational field of the earth is the objective of gruvinetric geodesy. Five geodetic measurement systems are employed to provide simultaneous evaluation of their performence and to ensure highly accuratie measurements. The five geodetic systems are:

1. A radio Doppler system consisting of three coherent frequencies for Doppler-shift determinetion of the precise orbit.

2. A radio ranging system which receives and retrensmits ground based radio signals sent in sequence from four stations. The range is measured by observing the total phase shift of an accurately known modulation frequency.

3. A range and range rate system which is used to determine the changing range and radial velocity of the satellite by measuring the phase difference and doppler shift of a signal transmitted from a ground station and retransmitted by the satellite.

4. Corner cube quartz laser reflectors to determine the position of the satellite by measuring the time increment required for the laser beam to travel from the station to the satellite and back to the station.

5. An optical beacon system to be photographed against a background of stars to provide angle measurements.

GEOS-A is the largest and most complete satellite ever constructed exclusively for the study of geodesy. It was designed and built for the National Neronautice and Spacc Administration by The Johns Hopkins University Applied Physics Laboratory. Scientific and engineering direction of the project was provided by Dr. George C. Weiffenbach the project sclentist and Ralph E. Willison the project 
engineer. An artists conception of the spacecraft is presented in Fig. 1. It weighs $386.6 \mathrm{lbs}$. and is an eight-sided truncated pyramid. Fach of the 16 flat surfaces carries a panel of solar cells to convert solar energy into electricity.

For the GEOS-A mission an earth pointing satellite is desirable because it makes optimum use of the radiated and reflected optical and radio power. The most severe requirement of the stabilization system was imposed by the optical beam pattern. This system was designed to compensate for atmospheric attenuation with large zenith angles on the assumption of achieving earth pointing accuracy to within 5 degrees. Fig. 2 illustrates the optical beam pattern of the lamp-reflector combination vs. the angle off the longitudinal axis of the spacecraft. A comparison with the optical pattern of the ANNA $1 B$ satellitc is prcsentcd.

\section{Attitude Determination System}

The attitude determination problem is defined mathematically as the evaluation of a transformation matrix which relates the orientation of the spacecraft to some specified reference coordinate system. The nine elements of this matrix are direction cosines and, of course, are dependent; they can be expressed in terms of three independent variables. The transformation matrix can be determined as a function of time if two vectors can be specified simultaneously in both the satellite and reference coordinate systems. These vector components, six scalar quantities in all, will provide redundant information for the evaluation of the three independent variables of the transformation matrix so that in-flight calibration of the attitude system and statistical estimation of the attitude is possible. Two rather well defined vectors which can be measured in the spacecraft with a minimum expenditure of weight and power are the unit vector of the satellite-sun line and the vechor geonagnelic field. On GEOS-A the measurement of these two vectors forms the basis of the attitude detection system.

The instrument to measure the geomagnetic field components consists of three second-harmonic type flux-gate magnetometers. Calibration was performed at the Naval Ordnance Laboratory ${ }^{1}$. In addition, partial calibration of the instrument can be achieved in-flight by superposition of known magnetic biases on the three detectors sampling the ambient magnetic field.

The satellite-sun unit vector components are measured by an array of specially designed detectors utilizing analog solar cells. After considerable study at APL a system consisting of three types of detectors evolved 2,3 . Each sensor module is designed to contain: 1) an analog cosine sun sensor having a response grossly approximating a cosine curve as a function of the angle of incidence; 2) a detector which has a linear response in the vicinity of normal incidence; 3) a combination of two detectors providing a step response at each of two angles in the vicinity of normal incidence, see Fig. 3. Flight hardware, selected on the basis of similarity of response characteristics, is calibrated before mounting on a spacecraft.

Five solar detector modules were mounted on the GEOS-A spececraft, One module was mounted so as to be pointing in a direction parallel to the gravity-gradient boom of the spacecraft, hereafter referred to as the $+Z$ direction, and the remaining four modules were mounted around the equator of the spacecraft pointing in mutually orthogonal directions denoted hereafter as $+X,-X,+Y$, and - $Y$. No module was mounted so as to point in the $-z$ direction since in the normal gravity-gradient stabilized orientation the $-\mathrm{Z}$ axis is directed earthwerd. To minimize the effects of reflected light from the earth, shades were used below the equatorially mounted modules.

Experience has shown that the calibration constants for analog cosine detectors change during flight. Black has developed a program for recalibrating these instruments in t'light ${ }^{4}$. After recalibration, attitude data is processed by the Satellite Attitude Determination program (SAD), also developed by Black 5,6 . Th is program requires the orthogonal vector components of the earth's magnetic field vector and the orthogonal vector components of the satellite-sun unit vector, both measured in the satellite's coordinate system.

\section{Stabilization System Description}

Gravity-gradient stabilization utilizes the interaction between the inertia ellipsoid of the spacecraft and the gravitational field of the earth to provide geocentric orientation. Initial misorientation and perturbing torques induce satellite motion about its equilibrium position so that a damping schcme must be provided to dissipate this energy. Passive stabilization and damping offer the significant advantages of high reliability and a long lifetime.

The GEOS-A stabilization system consists of a single motorized extendible boom manufactured by the DeHavilland Company; at its end is a General Electric magnetically anchored eddy current damper 7 . The boom motor is controlled by ground command and backed up by an aubomalic stup switch activated by detents on the boom tape. This system provides bi-stable equilibrium about any axis normal to the local vertical. As desired for thermal uniformity there is no preferred orientation about the longitudinal axis.

A preliminary analysis indicated that this system, which would weigh approximately ll lbs, would meet two stabilization requirements: 1) operational status within 15 days at"ter Launch, and 2) a maximum steady-state libration amplitude of. 5 degrees. An important consideration in the selection of this system was that it had been successfully demonstrated in orbit. The emphasis on this factor was consistent with the mission, in that GEOS-A is basically a gendetic satellite not a gravity-gradient experiment.

The launch vehicle procured was the new improved Delta in which the last stage is spin stabilized. When separation occurs, the spacecraft rotates at a rate of approximately $150 \mathrm{rpm}$. A yo-yo despin device reduces this rate to about 1 to $3 \mathrm{rpm}$. As a despin backup, three orthogonal ferromagnetic rods encased in aluminum jackets are provided. These act as an eddy current despin device at high spin rates.

Proper stabilization of the satellite can be insured if the extension of the boom is initiated when the boom axis is pointing upwards and within 
55 degrees of the local vertical. However, there was no assurance that this orientation would be obtained during a pass over the command station at the Applied Physics Iaboratory. Another factor was that hazardous temperatures could be reached by the spacecraft which was thermally designed to operate as a gravity-gradient satellite. Both of these considerations indicated that boom extension might need to be initiated when the boom axis is in a non-preferred direction possibly resulting in upside-down capture. Inversion of the spacecraft could then be accomplished by a properly timed sequence of boom retraction and extension.

The eddy current damper designed and built by the General Electric Company consists of a magnet assembly which is free to lock onto the magnetic field of the earth. Rotation of the magnet assembly relative to a conducting spherical shell induces eddy currents in the conductor which impedes the motion of the spacecraft. To prevent physical contact between the magnet and the conducting sphere a diamagnetic shell of pyrolytic graphite is used as a centering device.

\section{Attitude Simulation}

The analytical theory upon which passive gravitygradient stabilization is based is well known. The analyses, however, tend to be complicated by the non-linearity and coupling of the equations of motion and are intractable without simplifying assumptions about the perturbing forces. The three non-Iinear differential equations for the attitude motion of a spacecraft in orbit about a gravitating mass yere developed in terms of Lagrangian mechanics. The center of mass of the satellite is constrained to an orbit of modest eccentricity having a longitude of the ascending node and an argument of perigee which are linear functions of time. These secular variations result from the even zonal harmonics of the gravitational field, principally the $J_{2}$ term. The coupling between orbilal and body inotions of the spacecraft is neglected. The attitude is expressed in terms of a general set of Euler angles because equations of motion in terms of any one set of these variables always have a singularity. This generality allows the use of a durl set of angles to specify the attitude without restrictions.

A rather general digital computer program titled Digital Attitude Simulator (DAS) has been developed which is applicable to a wide class of satellite configurations. It includes the effects of gravity-gradient torques, residual dipoles, solar radiation pressure, thermal distortion of gravitygradient booms and passive dampers of the eddy current and hysteretic types. A high order expansion of the rotating geomagnetic field in terms of spherical harmonics is included. The integration of the non-linear second-order differential equations of motion over the time domain is accomplished by a fourth-order Runge Kutta integration.

The eddy current damper is simulated on the assumption that 1ts magnet assembly is locked to the geomagnetic field. This is valid for the rather slow rates of motion of the spacecraft relative to the magnetic field and the large magnetic moments of the magnet assembly which are used. The magnitude of the damping torque is proportional to the angular velocity of the conducting shell relative to the magnet assembly. The thermal distor- tion of the gravity-gradient booms is handled in a quasi-static manner. Each boom is assumed to bend with a constant radius of curvature in the plane containing the undeformed boom and the sun. The boom deformation results in changes in the mass distribution parameters. The radiation pressure is computed for the booms in their undeformed position. That part of the incident radiation which is reflected is a function of the surface characteristics and is in general assumed to be of both the speculer and diffuse types. The effects of aerodynamic torques are negligible at the altitudes of interest.

A modification of the general program is used to analyze inversion maneuvers by taking into account the time dependent mass properties of the spacecraft. It is assumed that the boom retraction and extension rates are different and are polynomial functions of time.

Prelaunch Design Study

Prelaunch design studies were carried out independently by the Applied Physics Laboratory and the General Electric Company. In general, there was very good agreement. At APL the design study was performed by utilizing the general digital simulation described above. For this particular spacecraft and orbit the mejor perturbing torques arise from the gravitational, magnetic, and solar environments. The gravitational field, through the orbit eccentricity, induces a steady-state pitch libration. A linear theory in Appendix A gives an approximation to the amplitude and frequency of the perturbation. The magnetic torques arise from the interaction of the damper and residual dipole with the geomagnetic field. The coefficients used in the spherical harmonic expansion of the field constitute the Jensen-Cain model which has an rms accuracy of 9 percent for order 2 (8-terms) and 1 percent for order 4 (24-terms) 9 .

sludies of the transient and steady-state performance of the spacecraft were made for the nominal orbit which had a perigee of $600 \mathrm{~nm}$ and an apogee of $800 \mathrm{~nm}$. The eccentric orbit, which is undesirable for accurate stabilization, is necessary for accurate gravimetric geodesy for which the perigee need be well defined. The nominel orbit parameters and mass properties of the spacecraft are given in Table I.

The requirement on the transient performance of the stabilization system was that the spacecraft be in operational status, that is correctly oriented and damped to near sterdy-state, within 15 days after launch. This 15-day interval includes despin from about 1 to $3 \mathrm{rpm}$ to near orbital rate, waiting for favorable orientation of the longitudinal axis, erection of the stabilizing boom, damping to steadystate and, if required, the inversion maneuver and subsequent demping.

Approximations to the time constants of the despin and libration motions are possible. During the despin the large angular velocities of the spacecraft induce rotational motion of the magnet assembly so it is not locked to the magnetic field. The simple exponential law for eddy current damping which gives a time constant proportional to $I / c$ is optimistic. The amplitude of the libration motion after boom extension depends primarily on the inftial orientation of the longitudinal axis. 
The preferred orientation is that the boom axis is pointing up and near parallel to the local vertical. As the boom is extended, the work done by the gravitational forces will be small so there is a tendency to conserve angular momentum. The large inertia change will reduce the rate of rotation about all. axes except about the longitudinal to near zero. Since the equiliorium orientation of the gravitygradient satelilite has an in-plane angular velocity of one cycle per orbital revolution, pitch librations will result. For this reason, a study of the pitch motion best illustrates the effectiveness of the damper. A linearized solution for the transient pitch libration applicable to polar and near polar orbits is given in Appendix B. The time constant of the envelope of the transient response is proportional to $I / c$, as was the despin time constant. This solution also shows that, as expected, the damper induces a disturbing torque which is inversely proportional to $I / c$. Any improvement in the transient performance by decreasing $I_{p} / c$ will result in a larger disturbing torque and poorer steady-state performance. Preliminary estimates indicated that for boom lengths of 50 to 60 feet damping coefficients of 60,000 to 80,000 dyne-cmsec would satisfy the transient requirements. Preliminary simulation results indicated that this configuration would also satisfy the steady-state requirements.

A contract was then let to the General Electric Company for the fabrication of the damper and analysis of the stabilization system.

Concurrent with the fabrication of the satcllite, a detailed simulation study of the steady-state performance was initiated. For GEOS-A the steadystate librations result principally from the orbit eccentricity, magnetic damper, residual magnetic dipole, radiation pressure and thermal distortion of the gravity-gradient boom. It was recognized that the magnet assembly of the damper, which was not caged during launch could induce a residual magnetic moment in the batteries which are adjacent to it. Experiments confirmed this and provided bounds for the magnitude of the residual magnetic moment of the spacecraft 10 . This also meant that the magnetically anchored damper would be ineffective during the despin phase since its magnetic assembly would lock to the batteries. This problem could be circumvented by extending the boom a small distance. Once the characteristics of the damper had been finalized, by the General Electric Company, to a weight of $7 \mathrm{lbs}$, a damping coefficient of 70,000 dyme-cm-sec and a pole strength of 25,000 pole-cm, the remaining free variable in the steady-state analys is was the boom length. An increase in boom length, which increases the inertia of the system, tends to minimize the effects of the residual dipole and eddy current damper but increases the effects of radiation pressure and thermel bending. Therefore some optimum boom length exists which would minimize the total steady-state amplitude. Preliminary results indicated that a boom length of 50 ft would meet the 5 degree requirement. The boom tape was cut at 56 feet to provide a margin of 6 feet for any contingency, and a detent made in the tape at the $50 \mathrm{ft}$ length to provide automatic motor shut off.

Subscquent analysis by the General Electric Compeny and APL indicated that the $50 \mathrm{ft}$ length would not meet the five degree requirement over some portions of the spacecraft's lifetime. The amplitude of the solar Induced libration is a function of the relative positions of the orbit and the sun. A brief analysis of the twice orbital roll component of the solar forcing function indicated that the maximum roll amplitude is a function of the angle between the earth-sun line and line of nodes and the amount of the orbit that is shadowed. The analysis indicated that for the naminal orbit the maximum static roll amplitude induced by thermal-bending occurs when this angle 1 s 65 degrees and when perigee is in the shade, see Fig. 4. Digital simulation results, also given in Fig. 4, confirmed this analytical theory and indicated that for perigee in the shadow a maximum roll amplitude of 8.5 degrees was possible for a $50 \mathrm{ft}$ boom. Simulation results for 40, 50, and $60 \mathrm{ft}$ boom lengths are given in Fig. 5 . These results indicated that the 40 ft boom would satisfy the steady-state requirements under the worst possible case of solar aspect and location of perigee. Since the maximum amplitude appeared not to be very sensitive to small errors in boom length, it was decided that the proper length could be obtained by timing the boom extension and counting the number of turns of a gear in the motor drive.

Estimates of the coast time for the inversion maneuver indiceted that the total time required to retract the boan, coast, and extend the boom precluded the operation during a pass over a single station. However, the maneuver could be performed over an arc of the orbit covered by two ground stations whose coverege only slightly overlapped. The NASA STADAN Station at the University of Alaska in Fairbanks together with the Applied Physics Laboratory station at Howard County, Maryland met this requirement.

Post-Launch Analysis

GEOS-A was successfully launched into orbit at 1836 UI on day 310 in 1965 from the Eastern Test Range. The spacecraft was officially designated $196589 \mathrm{~A}$ and titled by the National Aeronautics and Space Administration - Explorer XXIX. While the boost phase of the launch was normel, the second stage apparently burncd to depletion. This resulted in obtaining the target perigee of 600 nautical miles but an apogee of 1230 nautical miles which is 430 nautical miles higher than planned. On the first pass over Alaska the spin rate was observed to be about one rpm. This confirmed the successful deployment of the yo-yo despin device. No reduction in spin rate was observed during the next 14 hours indicating that the magnetically anchored eddy current damper was indeed locked onto the batteries of the spacecraft.

The extension of the boom to its 3 foot detent was commanded from the Applied Physics Loboratory during the beginning of the 1212 UT pass on Day 317. This operation was completely successful. By observing the decay rate over several passes a time constant of 100 minutes was determined. By 1900 UT on the same day the spin rate was observed to be essentially zero. After despin, the spacecraft was observed, through telemetered magnetometer data, to maintain a near fixed orlentation with respect to the geomagnetic field. The residual magnetic dipole induced by the damper resulted in the spececraft being near magnetically stabilized. Reduction of the magnetometer data, by Mobley, 
resulted in the direction cosines of the residual magnetic moment vector in the spacecraft's frame of reference ${ }^{11}$.

As described above, the plan to stabilize the spacecraft was to extend the boam to 40 feet when either the boom axis achieved an orientation which would ensure proper capture or the battery tempere tures approached dangerous levels. On the 805 UT pasa on day 312 over the Applied Physics Laboratay the battery temperatures were observed to be below the lower flight acceptance limit so the boom was extended. The motor was started at 819 UT and stop ped at 827 UI for an elapsed time of 460 seconds. This time interval corresponded to the required time for the boom to extend to about 40 feet when tested on the ground. The boom length was also inferred from telemetered data indicating the number of revolutions of a gear in the motor drive. This method indicated that the boom length was $36.8 \pm 1 \mathrm{ft}$. On subsequent passes, the temperature increased to nominal values and magnetometer data confirmed that gravity-gradient capture was achieved. Unfortunately the spacecraft was inverted. since the solar detectors had earth shades, these earth shades now became sun shades and prevented the solar detectors from being fully illuminated. Consequently, no definitive experimental attitude data could be obtained.

At this time a simulation study of the inversion maneuver was undertaken utilizing the best estimate of the actual boom length and tracked orbjt. The purpose of the study was to determine the coast time interval which would maximize the probability of success of the maneuver. Station alerts based on the tracked orbit indicated the times favorable for the two-station maneuver. A decision was made to attempt it at 1642 UT on day 317. The 5 dey interval frun time of gravily-grudient capture allowed most of the transient motion to be damped out. The sequence of events in the maneuver was: to retract the bocm to its $15 \mathrm{ft}$ detent, and after the coast phase, to reextend the boom. It was decided to reextend the boom to the $50 \mathrm{ft}$ detent in case a second inversion maneuver would be required. The optimum boom length could also be obtained more accurately at some future time by retraction from the $50 \mathrm{ft}$ detent rather than meas ure the length by timing and counting gear revolutions during the inversion meneuver.

Different quadratic hoom extension and retraction rates obtained from ground experiments with the GEOS-A boom were used in the simulation. The major uncertainty besides initial boom length was in the pitch librational motion at the beginning of the boom retraction phase. Since the major pitch disturbing torque arises fram the orbit eccentriclty, a good approximation to the pitch motion could be obtained fram the linear theory given in Appendix A. The results of the simulation study are given in Fig. 6. The nominal initial con ditions referred to are those computed from Eq. (A.8) at the mean anomaly corresponding to 1642 UT on day 317 . Small errors in the inftial pitch rate have a much greater effect on the optimum coast time than small errors in pitch orientation. To study this phenomena, runs were made in which pitch rates corresponding to pitch librations of \pm 3 and \pm 5 degrees were added to the nominal inftial conditions. A const time of about 19.25 minutes was selected as that which would give the highest probability of success.

The inversion maneuver was initiated at the NASA STADAN station in Alaska and completed over the AH station. The boom retraction and extension phases took 295 and 481 seconds respectively which compare to the ground test values of 282 and 485 seconds which were used in the simulation. The differ ence in boom retraction time indicated that the boom length could have been at the upper limit of the estimated length. Although lack of experimental attitude data, larger then nominal eccentricity, and uncertainty in bocm length combined to minimize the probability of success of the inversion maneuver, surveillance of the attitude determination system during subsequent passes confirmed rlght side up capture.

A simulation study was then made to determine the performance of the spacecraft with the $50 \mathrm{ft}$ boom in its actual orbit and to determine the boom length which would best meet the steady-state libration requirements. A run depicting the translent motion of the spacecraft is given in Fig. 7 . The steady-state response of the spacecraft, as mentioned earlier, is a function of the angle between the line of nodes and the earth-sun line and the position of perigee. The node has a precessional rate of about 2.24 degrees per day. Every 111 days the sun will have completed one revolution with respect to the orbit and there will have been four periods of increased roll libration amplitude. However, because of the increased altitude of apogee the effect of the thermal bending in roll is smaller than observed for the nominal orbit. An extrapolation indicated that the worse case occurs near day 280 in 1966 when perigee is in shade. At this time the simulation indicated that the deviation from local vertical is less tha 5 degrees about 65 percent of the time and reached a peak of 7.5 degrees. The solar effect is minimized when the sun is in the orbit plane; at this time the peak libration angle is about 5.5 degrees. During the time of maximum solar effect, a boom length of 40 feet would result in deviations from the local vertical being under 5 degrees about 80 percent of the time and a peak amplitude of 6 degrees. Further reduction of the boom length would have little effect on the deviation from local vertical since the pitch libration dominates for the $40 \mathrm{ft}$ length case.

Post-Iaunch Attitude Detection System Performance While performance of the magnetometer system was satisfactory, the performance of the solar detection system was disappointing. Soon after launch data indicated that both the $+X$ and $-X$ linear detectors were not functioning. In addition, all pairs of calibration detectors exhibited a onestep response in place of the expected two-slep response curve 1llustrated in Fig. 3. The output of the $-\mathrm{X}$ cosine detector also exhibited an abnormal response as a function of solar angle of incidence and the opening of $a$ ground connection in this module on day 359 precluded the possibility of obteining meaningful attitude data after this date.

The abnormal response of the $-\mathrm{X}$ cosine detector is illustrated in Figs. 9 and 10. In Fig. 9 a plot of the TM output illustrates that for some pusses the response was a discontinuous function of time. Abnormal response of this detector was also observed whenever the transition of illumination from 
the $+X$ to the $-X$ cosine detector occurred. This phenomenon, illustrated in Fig. 10 for a pess on day 329 when the sun is nearly in the plane of the orbit, produced abnormal attitude results. As illustrated by Figs. 10 and II, the response of the $Y$ and $Z$ solar cosine detectors and all magnetometers indicated a continuous motion of the satellite. The rate of change of the output of the $+X$ and $-x$ cosine detectors in the vicinity of the transition region compares favorably to the orbital rate of the satellite. A lag in the response in the $-X$ cosine detector induced an apparent phase shift in the experimentally determined utti.tude of the satellite as illustrated in Fig. 12. For the portion of this pass over APL and the beginning of the pass over Santiago, where the $+\mathrm{X}$ cosine detector is lit, good agreement is obtained between the experimental results and the digital simulation and linear eccentricity theory. For the remainder of the pass over Santiago the $-\mathrm{X}$ cosine detector is lit and the phase shift induced by this detector causes the difference between the experimentel results and the simulation results to increase to approximately 7 to 8 degrees in both pitch and roll and to nearly 5 degrees in deviation from the 10cal vertical. Abnormally high rates of motion are also associated with the changes in angles within this region. Statistical comparison of both portions of the pass with the digital simulation is given in Table II. Further indication of abnormal $-X$ cosine detector performance was obtained from the magnitude of the post-launch calibration constants. Calibration was effected from data taken in the vicinity of day 340 from four stations: Santiago, Johannesburg, Canberra, and AFL. A comparison of the prelaunch with the post-launch calibration constants is given in Table III A large decrease in magnitude of the calibration constants was observed for all cosine detectors with the exception of the $-X$ detector. A decrease in the solar calibration constants has been observed in ali satellites built by AFL. In GEOS $A$ the $-\mathrm{X}$ detector calibration constant actually increased. All of the above factors support the conclusion that the $-\mathrm{X}$ cosine detector was not functioning properiy and that the attitude data besed upon this detector should be disregarded.

Comparison of Theoretical and Experimental Attitude Deta

The agreement between the SAD experimental attitude and theoretical attitude of the spacecraft indicated by the simulation can be studied by exemining Fig. 12, the combined APL-Santiago pass on day 329. As discussed above, good agreement is obtained only over the portion of the pass during which the $+X$ solar detector is lit. The SAD experimental data, which utilizes the malfunctioning $-X$ solar detector, gives a physically absurd motion.

An indication of the agreement between the experimental and theoretical attitude can also be inferred from a comparison of the experimental and theoretical solar and geomagnetic data, see Figs. 10 and 17. Small differences in the date over all of the double pass is observed indicating good three axis att1.tude agreement. This also confirms yaw capture of the spacecraft by the geomagnetic field.

Since the $z$ detector data is sufficient to define the orientation of the $Z$ exis of the satellite, the very good agreement between the $\mathrm{Z}$ experimental data and the simulation results should be noted. At each data point the $\mathrm{z}$ magnetometer and solar data independently define two cones of position for the $\mathrm{Z}$ axis of the satelifite. The intersection of these two cones yields, in general, two possible orientations of the satellites' $Z$ axis. One solution must be discarded by its indication of an abnormally large deviation from the local vertical. The results of this simplified technique are presented and compared to the simulation results in Fig. 13. The spread at each data point is the uncertainty introduced by a one percent error in the experimental magnetometer and solar data - yielding nine possible combinations of input data. In general, the results of this simplified technique indicate extreme sensitivity to small errors in input data. A comparison of the SAD determination of attitude using redundant data with the simplified technique for the APT pass indicates the necessily for redundant data. It implies an error in $Z$ detector deta in excess of one percent. This comparison also indicates that the use of the simplified technique to determine attitude over the Santiago pass is questionable. However, good agreement was obtained at the end of the Santiago pass especially for the total deviation from local vertical.

The small difference between the total deviation from locel vertical as computed from the linear eccentricity theory and the simulation indicates that the effect of all other disturbing torques should be small. This is because the sun is nearly in the plane of the orbit; a geometric configuration which minimizes the roll disturbance. The simulation indicates a maximum total deviation of the $\mathrm{Z}$ axis from the local vertical of 4.5 degrees near the end of the Santiago pass.

Results for additional passes over APL, when the $+X$ solar detector is illuminated, are given in Figs. 14 to 16 together with results of the digital simulation and the linear eccentricity theory. Similar discrepancies at the beginning of each pass are noted for pitch and roll, but there is reasonable agreement in the lotal deviation from local vertical when this occurs. A comparison of the experimental data over the four passes shows similarities from pass to pess indicating that a steady-state motion has been obtained and that the attitude determination system is stable. A statistical comparison between the SAD experimental attitude data and the simulation results for these passes is given in Table IV.

The agreement between simulation and experimental attitude results indicates the successful performance of the GEOS-A stabilization system. The credibility of the digital simulation of the attitude motion of the gravity-gradient satellite has been supported. 


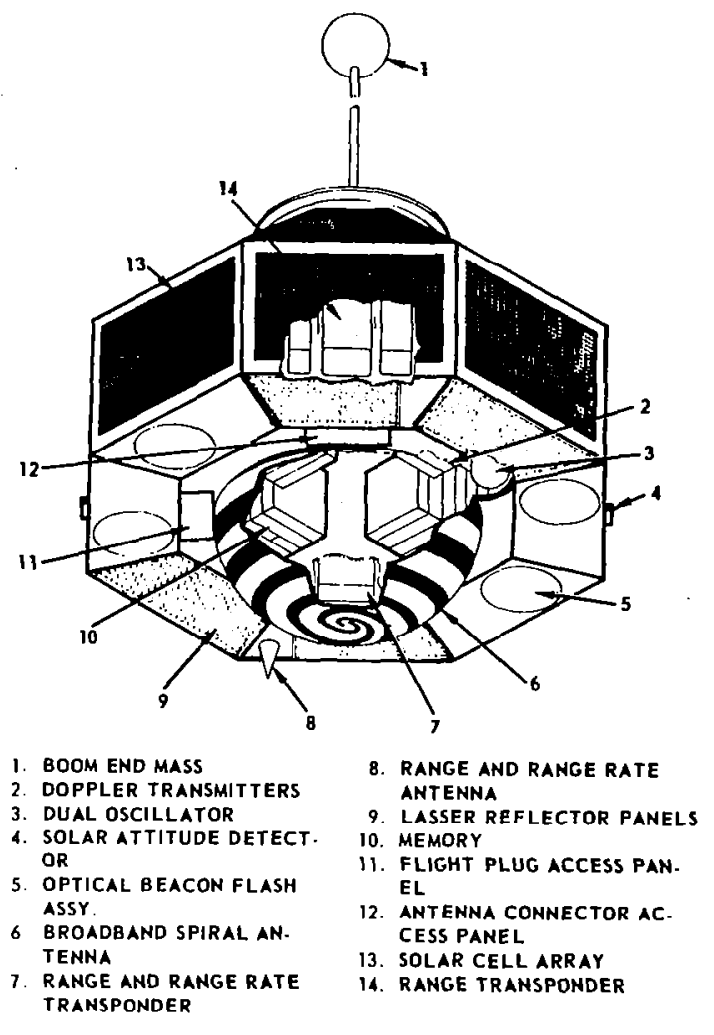

Fig. 1 GEOS-A SPACECRAFT

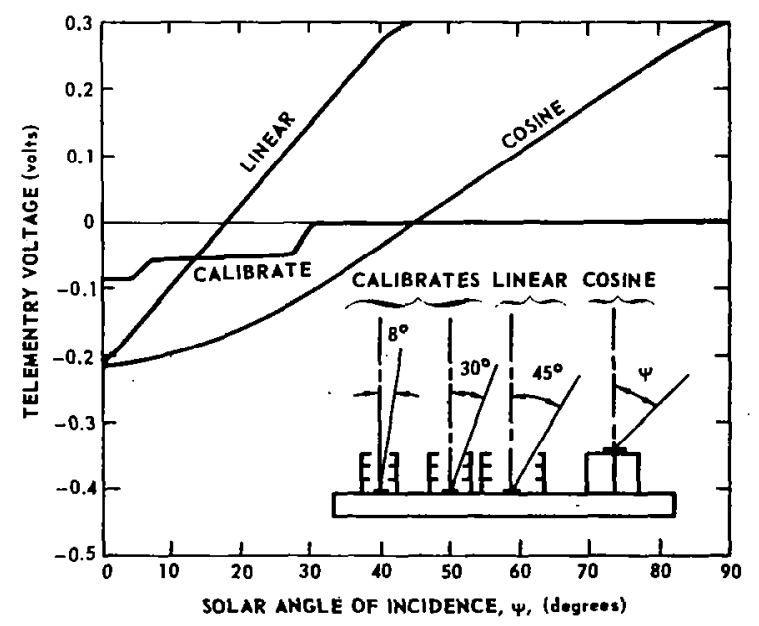

Fig. 3 GEOS-A.SOLAR ATTITUDE DETECTOR RESPONSE CURVES, $\mid 111$

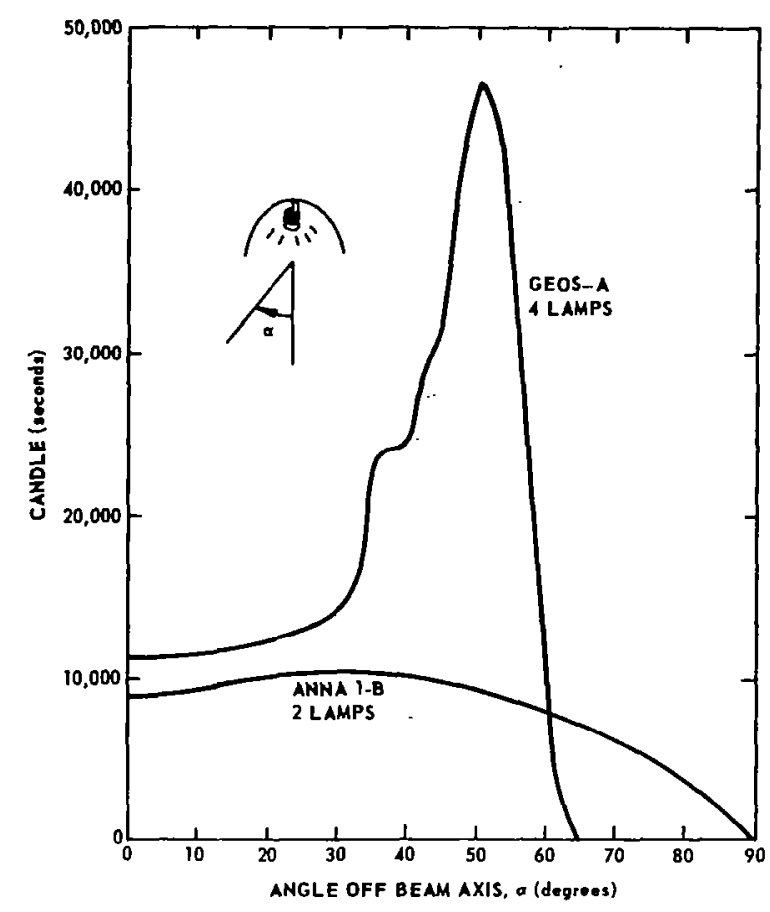

Fig. 2 OUTPUT OF 4 GEOS-A LAMPS FLASHED SIMULTANEOUSLY BASED ON PROTOTYPE LAMP-REFLECTOR MEASUREMENTS. ANNA BEAM PATTERN IS SHOWN FOR COMPARISON.

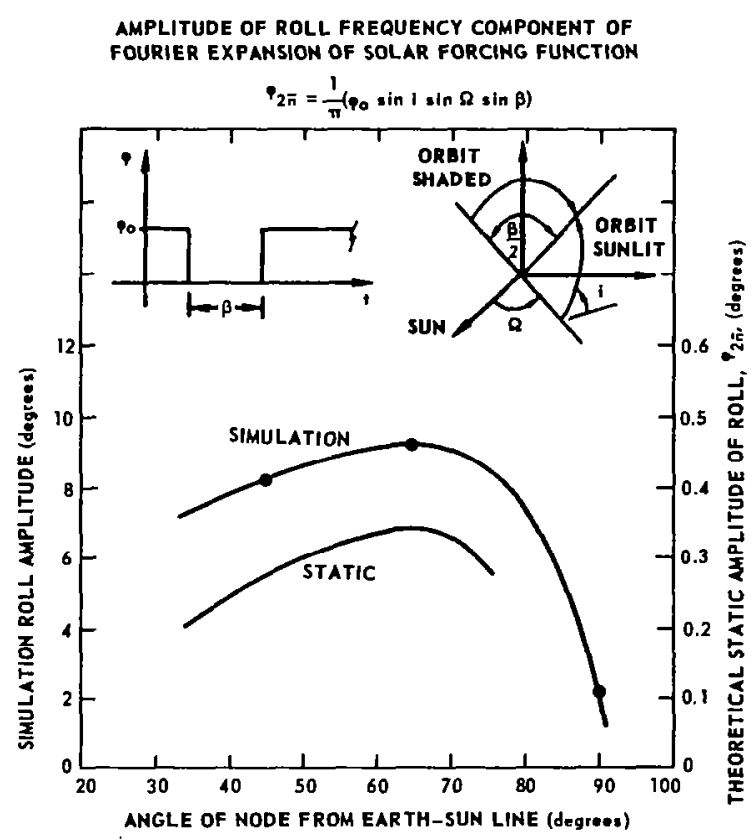

Fig. 4 AMPLITUDE OF ROLL ANGLE VERSUS ANGLE OF NODE FROM EARTH-SUN LINE GEOS-A IN NOMINAL ORBIT AND 50 FOOT BOOM LENGTH 


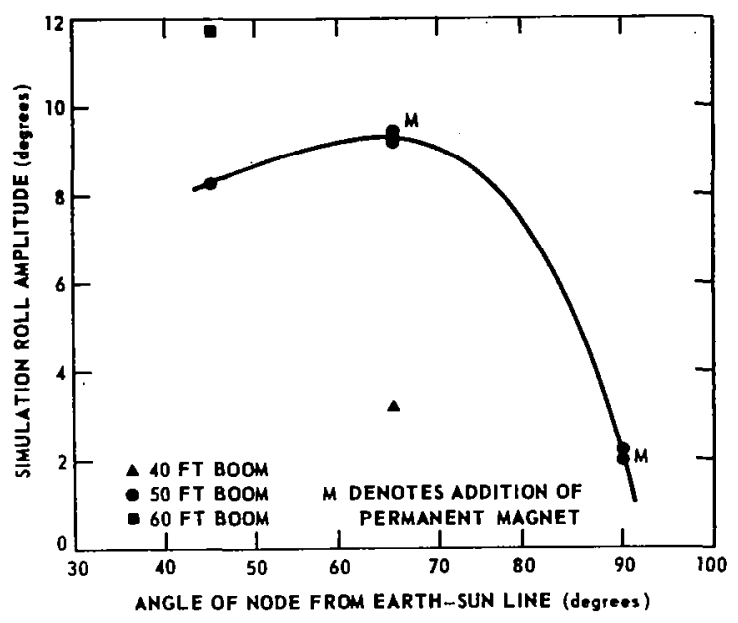

Fig. 5 AMPLITUDE OF ROLL ANGLE VERSUS ANGLE OF NODE FROH EARTH-SUN LINE, GEOS-A NOMINAL ORBIT

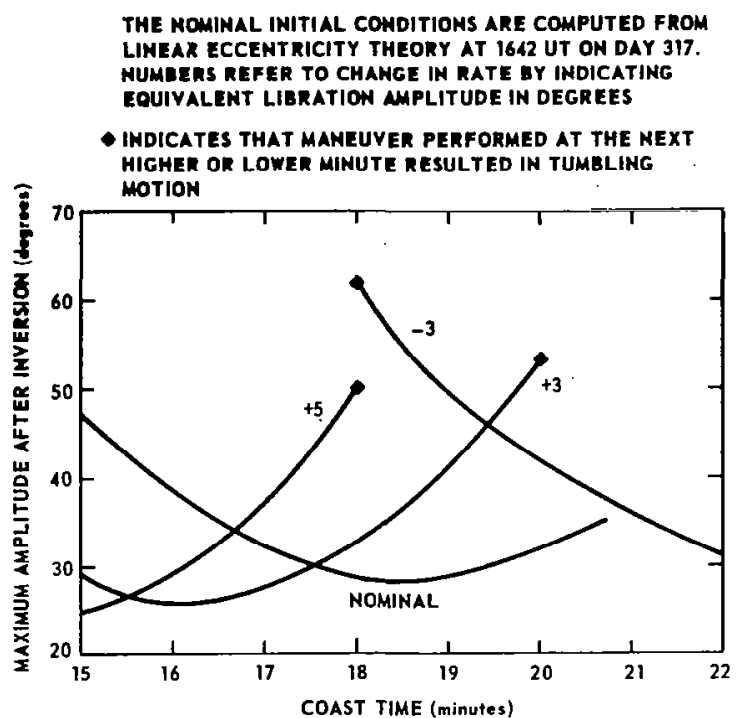

Fig. 6 GEOS-A INVERSION MANEUVER STUDY RESULTS. MAXIMUH AMPLITUDE AFTER INVERSION AS FUNCTION OF COAST TIME AND INITIAL ANGULAR RATE.
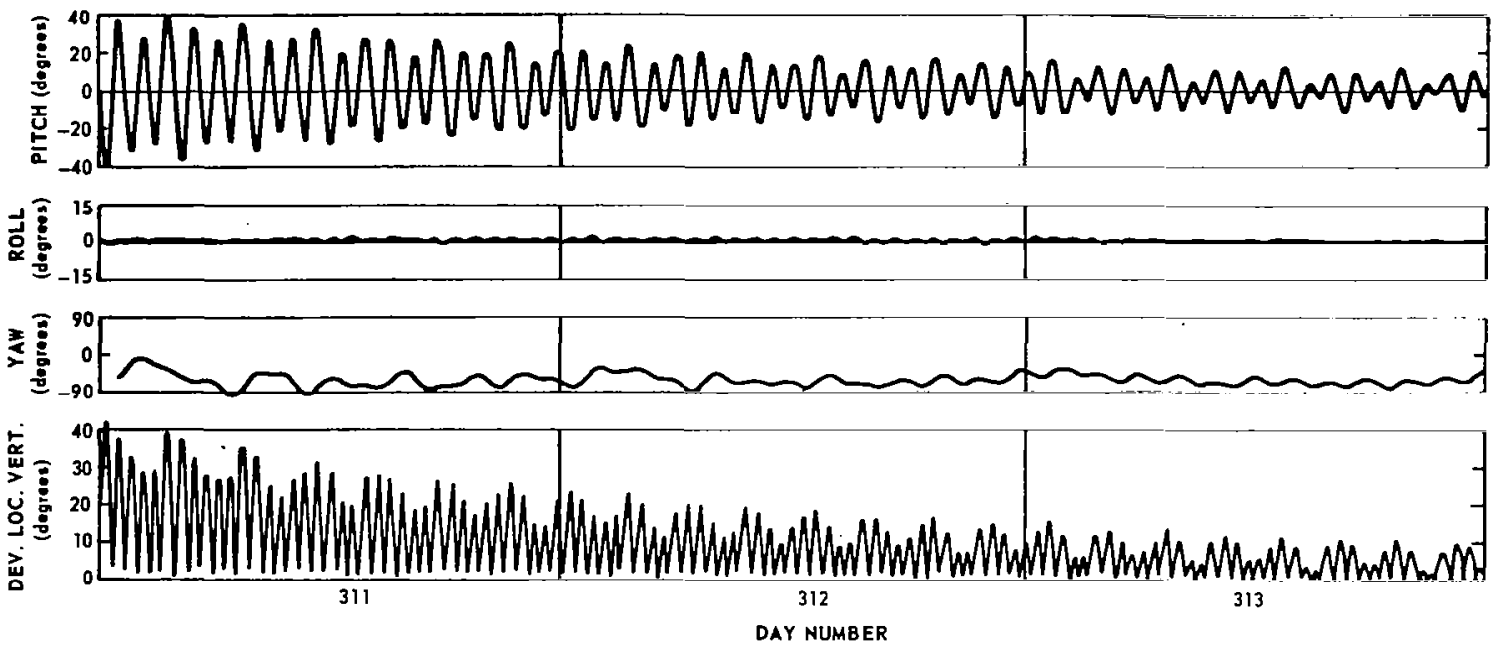

Fig. 7 GEOS-A TRANSIENT SIMULATION RUN

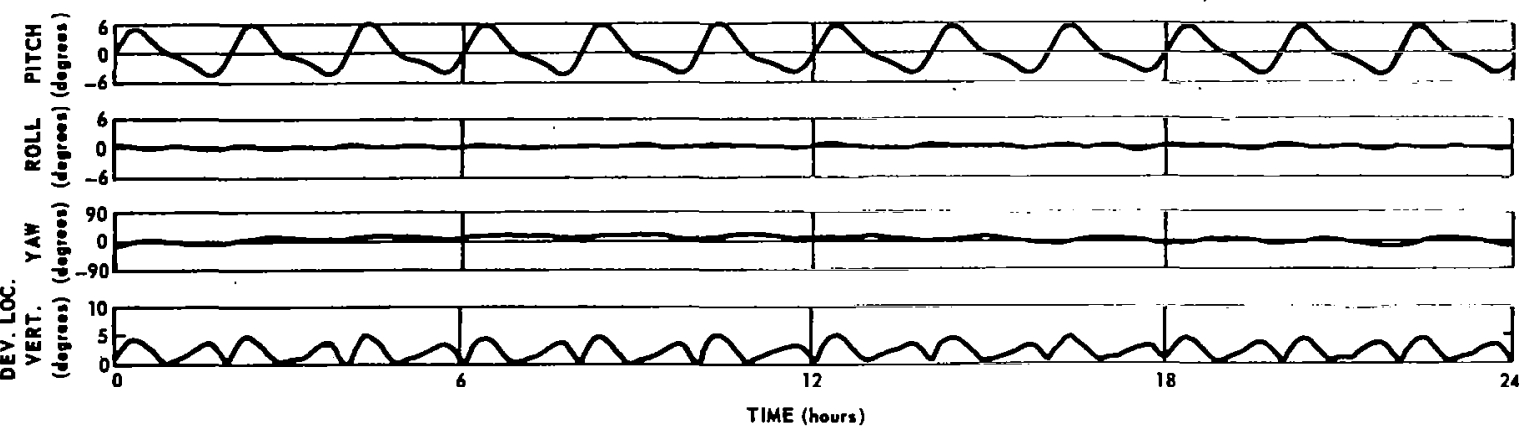

Fig. 8 GEOS-A STEADY-STATE SIMULATION RUN, DAY 329 


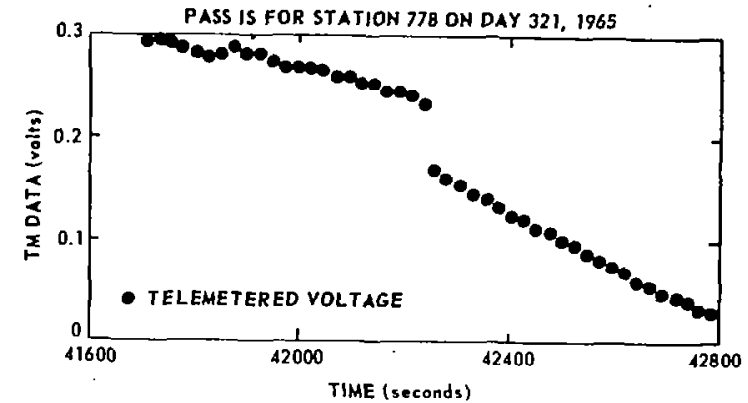

Fig. 9 GEOS -A TELEMETRY DATA ILLUSTRATING DISCONTINUOUS RESPONSE IN - $X$ COSINE DETECTOR

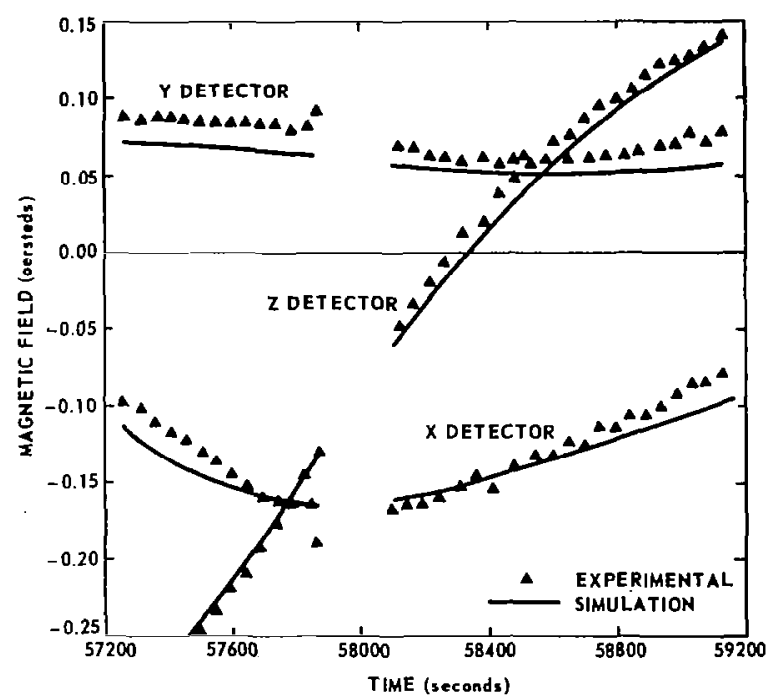

Fig. 11 GEOS-A MAGNETOMETER DATA FOR APL/SANTIAGD PASS ON DAY 329

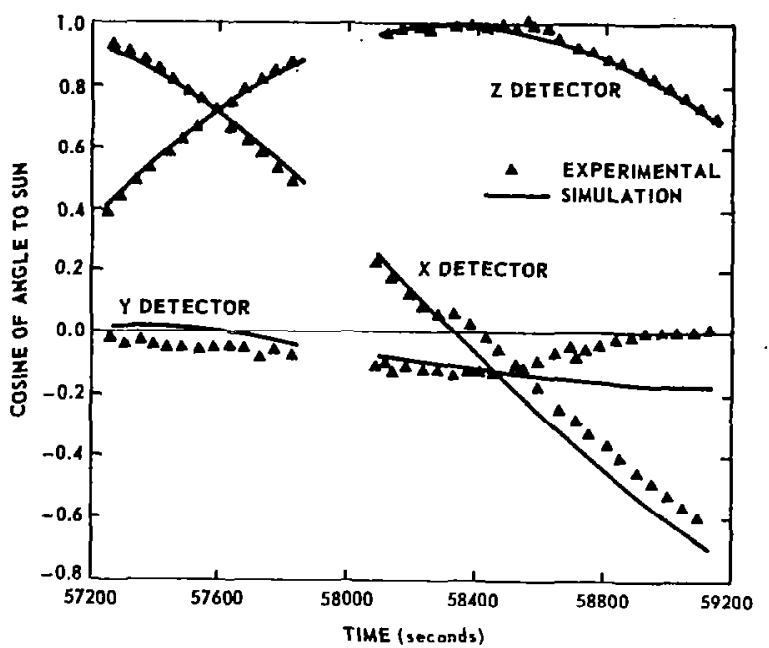

Fig. 10 GEOS-A SOLAR COSINE DETECTOR DATA FOR APL SANTIAGO PASS ON DAY 329
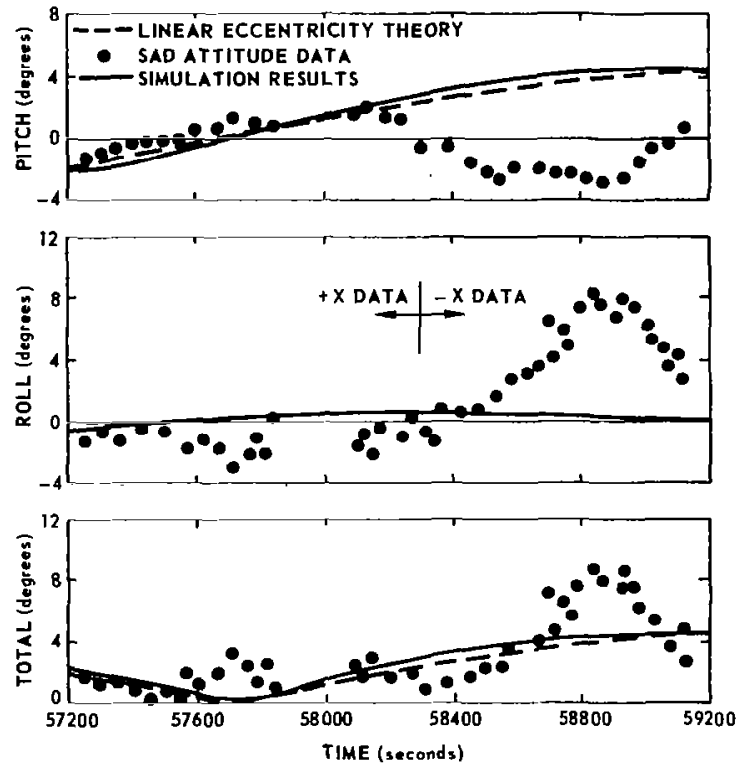

Fig. 12 GEOS-A ATTITUDE DATA AND SIMULATION RESULTS FOR APL/SANTIAGO PASS DAY 329 

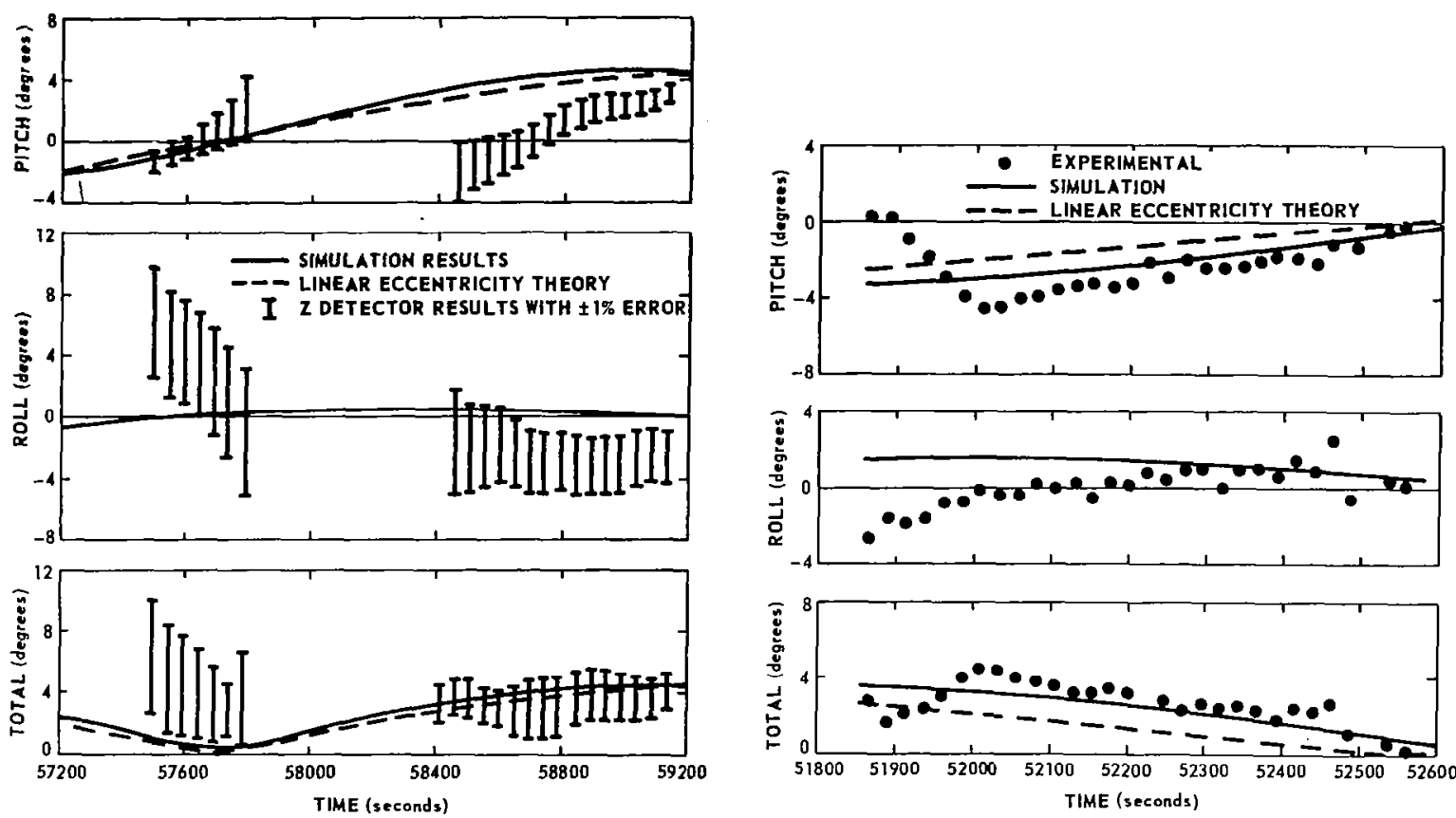

Fig. 13 SIMULATION AND Z DETECTOR RESULTS FOR APL 'SANTIAGO PASS DAY 329
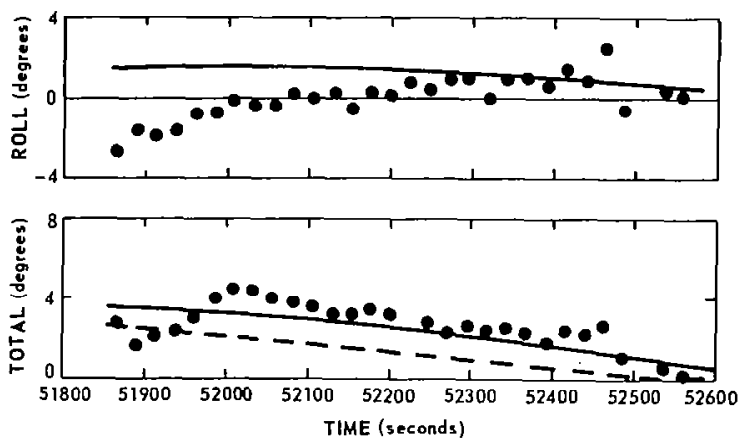

Fig. 14 GEOS-A ATTITUDE DATA AND SIMULATION RESULTS FOR APL PASS ON DAY 338
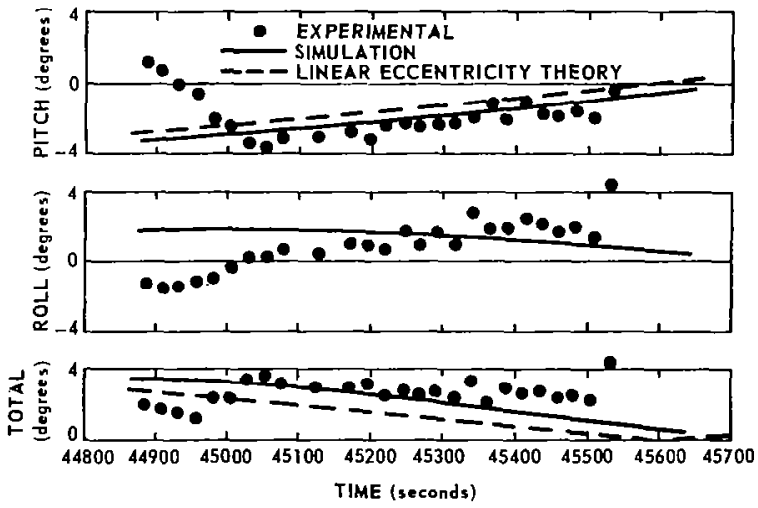

Fig. 15 GEOS-A ATTITUDE DATA AND SIMULATION RESULTS FOR APL PASS ON DAY 339
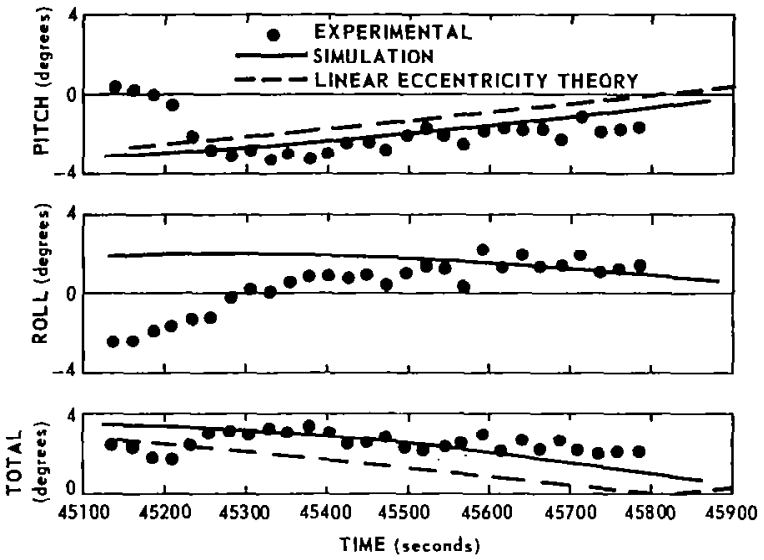

Fig. 16 GEOS-A ATTITUDE DATA AND SIMULATION RESULTS FOR APL PASS ON DAY 310 
Table III

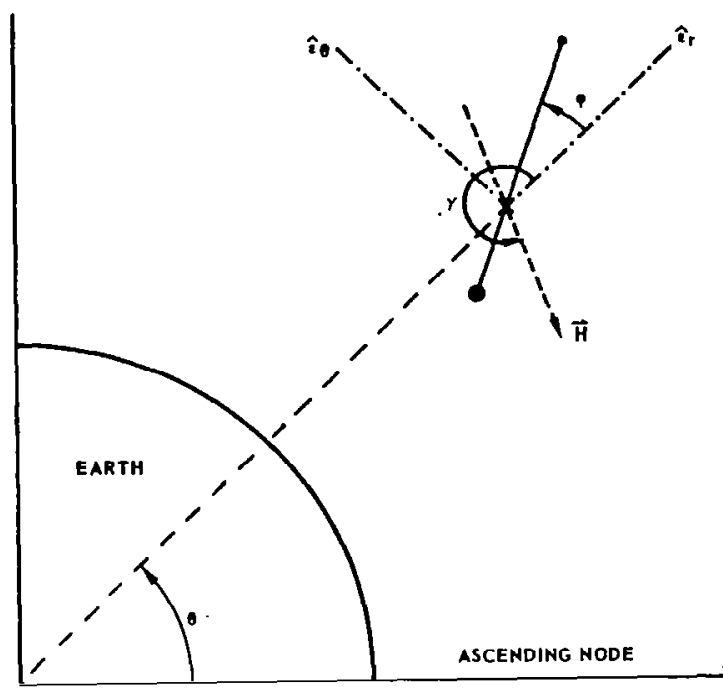

Fig. 17 IN-PLANE CONFIGURATION OF SPACECRAFT IN ORBIT

Table I

Satellite and Orbit Characteristics

Satellite characteristics in launch configuration $I_{x}=15.6$ slug ft?

$I_{\mathrm{y}}^{x}=17.4$ slug $\mathrm{ft}^{2}$

$I_{z}=20.8$ slug $\mathrm{ft}^{2}$

$M=386.6 \mathrm{lbs}$, mass

Satellite characteristics for $50 \mathrm{ft}$ configuration

$I_{x}=615.3$ slug $\mathrm{ft}^{2}$

$I_{y}=61.7 .0$ slug $\mathrm{ft}^{2}$

$I_{Z}=20.8$ slug $f t^{2}$

$\mathrm{A}=12,149 \cdot \mathrm{cm}^{2}$, radiation area

$r=175.3 \mathrm{~cm}$, radiation moment arm

$c=70,000$ dyne-cm-sec, damping coefficient

$\delta-28.9 \mathrm{~cm}$, thermal bending tip deflection

$\mathrm{P}_{\mathrm{x}}, \mathrm{P}_{\mathrm{y}}, \mathrm{P}_{\mathrm{z}}=-56.3$, 159., 250. pole-cm, dipole comp.

rbit characte

semi-major axis, $\mathrm{km} \quad 8073.5603$

eccentricity

inclination, deg

ascn. node, deg

arg. perigee, deg

mean anomaly, deg

rate of node, deg/day

rate of perigee, deg/day

time of perigee, day-year

.071922542

59.371434

7674.5410

.024

59.

40.256994 vuriuble

166.75751 variable

0

$-2.2457252$

65242004

0

$-2.62$

.84

variable

Table II

Statistical Comparison Between Attitude Data and Simulation Results for APL/Santiago Pass, Day 329

$\begin{array}{lcc} & +\mathrm{X} \text { data } & -\mathrm{X} \text { data } \\ \text { Pitch } & 0.88 & 5.84 \\ \text { Rol] } & 1.55 & 4.74\end{array}$

Analog Cosine Detector Calibration Constants

\begin{tabular}{lrrrrr}
$\begin{array}{c}\text { Description } \\
\text { of set }\end{array}$ & $+\mathrm{X}$ & $-\mathrm{X}$ & $+\mathrm{Y}$ & $-\mathrm{Y}$ & $-\mathrm{Z}$ \\
Prelaunch & .437 & .360 & .492 & .508 & .444 \\
Post-launch & .312 & .398 & - & .375 & .349 \\
& \multicolumn{3}{c}{ Table IV } & & \\
& & &
\end{tabular}

Statistical Comparison Between Attitude Data and Simulation Results for APL Passes on Days 338,339 and 340

\begin{tabular}{lccc} 
& \multicolumn{3}{c}{ RMS in degrees } \\
Pitch & Day 338 & Day 339 & Day 340 \\
Roll & 1.30 & 1.49 & 1.25 \\
Total & 1.76 & 1.79 & 1.98 \\
& 0.80 & 1.20 & .71
\end{tabular}

Appendix $\Lambda$

Steady-State Libration Induced by Orbit Eccentricity

In this appendix the pitch (or in-plane) motion of a gravity-gradient satellite induced by orbit eccentricity is considered. For small values of eccentricities and small librational amplitudes, the pitch equation becomes decoupled from the roll and yaw equations. An approximate analytical solution then becomes possible.

Euler's equation for the pitch motion of a satellite, depicted in Fig. 17, is given by

$I_{p}(\ddot{\theta}+\ddot{\phi})=T_{g}=\frac{3 k}{2 r^{3}}\left(I_{y}-I_{r}\right) \sin 2 \phi$

where $\mathrm{T}_{\mathrm{g}}$ represents the gravity-gradient torque.

For an orbit of modest eccentricity

$$
\begin{aligned}
\theta & =M+2 c \sin M+o\left(\varepsilon^{2}\right) \\
r / a & =1-\epsilon \cos M+o\left(\varepsilon^{2}\right)
\end{aligned}
$$

so that

$$
\begin{aligned}
\ddot{\theta} & =-2 \varepsilon \mathrm{n}^{2} \sin M+o\left(\varepsilon^{2}\right) \\
(a / r)^{3} & =1+3 \varepsilon \cos M+o\left(\varepsilon^{2}\right)
\end{aligned}
$$

Substituting Eqs. (A.4) and (A.5) into Eq. (A.I) yields

$\phi^{\prime \prime}+3 \sigma \phi=2 \epsilon \sin M+o\left(\phi_{\epsilon}\right)+o\left(\varepsilon^{2}\right)$

where

$$
\begin{aligned}
M & =n t ; n^{2}=k / a^{3} \\
(\cdot) & \equiv \frac{d}{d t}=n \frac{d}{d M}=n()^{\prime} \\
\sigma & \equiv\left(I_{r}-I_{y}\right) / I_{p}
\end{aligned}
$$

and it has been assumed that

$$
O(\phi)=O(\epsilon)
$$




$$
\phi=\frac{2 \varepsilon}{3 \sigma-1} \sin M+o(\epsilon)+o(\phi, \epsilon)
$$

which yields the induced pitch motion as a function of mean anomaly.

\section{Appendix B}

\section{Simplified Study of the Magnetically Anchored Damper}

In this appendix the damping and perturbing effects of the eddy current damper are examined. An analysis applicable to polar and near-polar satellites yields the damping rate and disturbing effect in terms of the damping coefficient and the inertio of the spacecraft.

Extension of the gravity-gradient boom usually occurs only after the spacecraft has despun to near orbital rates. The large inertia change which accompanies boom extension reduces this rate of rotation in inertial space to near zero about all axes except the longitudinal axis. Since the satellite in its stabilized position has an angular velocity in-plane of one cycle per orbital revolution, pitch libration about this equilibilum position will result. For this reason a study of the pitch motion best characterizes the damping and perturbing effects of the damper

The magnetic field for the satellite depicted in Fig. 17 which is assumed to move in a magnetically polar circular orbit, is given by

$$
\mathrm{H}=\mathrm{H}_{0}\left(\cos \theta \hat{\varepsilon}_{\theta}-2 \sin \theta \hat{\varepsilon}_{r}\right)
$$

The angle between the local vertical and the magnetic field vector is given by

$$
y=-\arctan \left(\frac{1}{2} \cot \theta\right)
$$

If the magnet of the magnet assembly of the damper is collinear with the local field, the motion of the assembly relative to the conducting shell is given by

$$
\dot{\gamma}-\dot{\phi}=\frac{2 \dot{\theta}}{I+3 \sin ^{2} \theta}-\dot{\phi}
$$

Experiments show that the torque exerted by the magnet assembly on the conducting shell is proportional to their relative velocity, $c(\dot{\gamma}-\phi)$; where $c$ is the damping coefficient.

For pitch motion of the satellite on a circular orbit, Euler's equations of motion become

$$
I_{p} \ddot{\phi}=T_{g}+T_{c}
$$

where

$$
\begin{aligned}
& T_{g} \equiv \frac{3}{2} \frac{k}{r^{3}}\left(I_{y}-I_{r}\right) \sin 2 \phi \\
& T_{c}=c(\dot{\gamma}-\dot{\phi})
\end{aligned}
$$

For $\phi$ small, Eq. (B.4) becomes

$$
\phi^{\prime \prime}+\frac{c}{n I_{p}} \phi^{\prime}+3 \sigma \phi=\frac{2 c}{n I_{p}\left(1+3 \sin ^{2} \theta\right)}
$$

where

$$
\begin{aligned}
\sigma & \equiv\left(I_{r}-I_{y}\right) / I_{p} \\
()^{2} & \equiv \frac{\mathrm{d}}{\mathrm{d} M}, M=n t
\end{aligned}
$$

The time constant, that is the time it takes for any disturbance to decrease to $e^{-1}$ of its initial value, is given by

$$
\mathrm{t}_{\mathrm{c}}=\frac{\mathrm{nI} \mathrm{p}}{\pi \mathrm{c}} \text { (orbital revolutions) }
$$

The time constant decreases and the disturbing torque increases as the ratio $\mathrm{c} / \mathrm{I}$ increases. This means that any improvement in transient

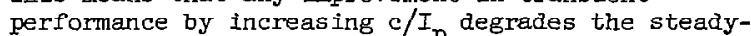
state performance. These resblts are valid for polar and near polar orbits. Digital simulation results indicate that $\mathrm{Eq} .(\mathrm{B} .8)$ is conservative.

\section{Acknowledgment}

This work was supported by the Geophysics and Astronomy Programs Directorate of the National Aeronautics and Space Administration Headquarters.

The authors are grateful to Mr. H.D. Black, Mrs. M. Jennings, and Mr. M. Sturmanis for processing the experimental attitude data and for providing useful information based upon their experience with the attitude determination problem.

Refexences

1. Nobles, H., "GEOS-A magnetometer calibration date and magnetometer coordinate system transformations, "APL Internal Memo S4P-2-109 (Oct. 1965).

2. Fischell, R. E., "Solar cell experiments on the Transit and TRACC satellites," Johns Hopkins University, Applied Fnysics Laboratory Report CM-1021, (May 1962).

3. Allen, W. E., "GEOS-A solar attitude detection system, electrical performance surmary," APL Internal Memo S4P-1-173 (28 Feb. 1966).

4. Black, K. D., et al, "Attitude determination utilizing redundant sensors," Pros. IV Int. Aero. Inst. Symp., The College of Aeronautics, England (21-24 Mar. 1966).

5. Black, H. D., "A Passive system for determining the attitude of a satellite," AIAA J. 2, 1350 (1964).

6. Jennings, M. W. "Programs to compute the satellite att1tude," APL Internel Memo; S1A-124-66 (8 April 1966).

7. Moyer, R. G., "Passive attitude control system analysis for the GEOS satellite," General Electric Spacecraft Dept., Document No.64SD4443 (Sept. 1965).

8. Pisacane, V. I., W. H. Guier, and P. P. Pardoe "General dynamical equations of motion of a multi-bodied satellite," (in preparation).

9. Jensen, D. C. and J. C. Cain, "An interim geomagnetic field," J. Geophys Res. 67, 3568 (1962).

10. Tossman, B., "GEOS-A dipole moments," APL Internal Memo S4P-2-085 (Sept. 1965).

17. Mobley, F., "Approximation to the GECS-A residual magnetic dipole," (private communication). 